\title{
On the Relationship between Modern Industrial Design and Traditional Craft
}

\author{
Ya'nan Zheng \\ Eastern International Art College \\ Zhengzhou University of Light Industry
}

\begin{abstract}
Under the industrial background of global diversification development with high-tech as the leading role, industrial design has obtained an unprecedented development opportunity. The correct design concept will influence the trend of design. Currently, product design is developing towards different direction with the guidance of various excellent design concepts, resulting in different styles. Modern industrial design concept is the core issue guiding the trends of industrial design; and design expression is not only the tangibility of concept, but also the tool for idea exchange and the starting point for practice. New concept shall re-examine the concept, category, essential characteristics and design objects of industrial design. Modern industrial design is an integral part of modern technology. From the horizontal dimension point of view, the design will have a particular spiritual and cultural psychological structure no matter what style it has, which is developed and accomplished in a certain cultural context, reflecting different values and aesthetic conception therein and the cultural style at that time. Even the most "anti-tradition" designer must take "tradition" as a negative reference to define and interpret their own thinking. Design has never been an individual behavior, from the explicit understanding such as media, language and expression means, to the hidden traditions such as cultural mentality, way of thinking and aesthetic viewpoint of design understanding, are influencing every modern industrial designer invisibly.
\end{abstract}

Keywords-modern industrial design; traditional crafts; traditional culture

\section{MODERN INDUSTRIAL DESIGN CONCEPT}

Under the development of global diversification and high-tech support, as a professional design system taking over history and future, industrial design is reflected as the integration of science and art, consolidating the characteristics of diversity, marginality and application, which is product of combination of psychology, physiology, behavior, plastic arts, materials science, engineering technology, manufacturing, marketing, system decision using creative thinking. With respect to single science, industrial design not only has an inseparable connection with it, but also has its own independent system and complete system architecture. Correct design concept will affect the trend of design. Currently, product design is developing towards different direction with the guidance of various excellent design concepts, resulting in different styles. So, what is modern industrial design? It is the core issue guiding the trends of industrial design; and design expression is not only the tangibility of concept, but also the tool for idea exchange and the starting point for practice. The new concept shall re-examine the concept, category, essential characteristics and design objects of industrial design. Based on the attitude of learning from history and facing the future, from the arts and crafts movement, Art Nouveau and various schools of modernism and postmodernism to the prevailing or nascent industrial design (including green design, humanized design, personalized design, bionic design and product semantics, etc.), modern design shall reflect the concern for multi-level needs of talents, concern for the environment and the social concern for design. The goal of green design is consistent with the common interests of all mankind, and mainstream design in future will not depart from this fundamental purpose. Under the guidance of this purpose, the world's industrial design will present a diversified development trend with coexistence of peoplecentered humanized design, fashion promotion, personalized design, and bionic design with natural learning and fun as well as product semantics proposed against high-tech era [1].

The ultimate goal of modern industrial design is to serve "people", and meeting people's needs is the design center. Therefore, in industrial design, the design concept of "people-oriented" shall be reflected around this principle, and accomplish product development according to people's psychological needs, behavior way, proportion of scale, as well as lifestyle and cultural background, living environment and other factors to enhance product value. The formation of industrial design in the modern large-scale industrial production and intense competition of commodity economy; its nature of multidisciplinary; obtaining the optimum matching between product and user is the fundamental design concept; and to make beautiful formative creation on the basis of integration of function, material and technology.

\section{RELATIONSHIP BETWEEN MODERN INDUSTRIAL DESIGN AND TRADITIONAL CRAFT}

Industrial design has developed rapidly under the development of global diversification and high-tech support. Therefore, with respect to survival and development of China's traditional crafts in modern times, overall inheritance is unrealistic and unscientific. To walk out a road of harmony and intergrowth between production and culture is the only way for industrial design in future, and of course it 
is also an opportunity for modern industrial development with characteristics. The relationship between traditional craft and modern industrial design is described in the following from three aspects of material, technology and value of traditional craft design.

Modern industrial design is an integral part of modern technology. From the horizontal dimension point of view, the design will have a particular spiritual and cultural psychological structure no matter what style it has, which is developed and accomplished in a certain cultural context, reflecting different values and aesthetic conception therein and the cultural style at that time. From the perspective of vertical dimension, the technological design at any age is closely linked with the then productivity and culture. Design form comes from culture; and people process all the relevant impression according to their experience (history and tradition).

Traditional culture influences modern industrial design. Although those modern designers, especially the avant-garde consciousness designer, always claim to abandon tradition, thinking that their work is "traditionless", but the reality could not be so, even the most "anti-tradition" designer must take "tradition" as a negative reference to define and interpret their own thinking. Design has never been an individual behavior, from the explicit understanding such as media, language and expression means, to the hidden traditions such as cultural mentality, way of thinking and aesthetic viewpoint of design understanding, are influencing every modern industrial designer intentionally or unintentionally.

\section{A. Relationship between Traditional Craft Materials and Modern Industrial Design}

In modern design activities, more and more designers realize the important influence on traditional craft design by material selection and application. At the same time, along with the higher requirements on innovative design approach and green design of traditional craft design by modern society, designers have begun to focus on the use of innovative materials. Design and materials are closely linked, and the essence of design activity is reasonable selection and application of materials. And the innovative application of material is a necessary requirement for development of modern design, and innovative use of materials, thus touches a new design direction.

1) Relationship between Traditional Craft Raw Material and Modern Industrial Design. Generally, the so-called traditional craft includes three meanings: First, a long history; second, the use of natural materials and the third is manually operated without the aid of modern technology. Among which, the use of natural materials is an important symbol of traditional crafts. According to recently released "National Arts and Crafts Industry Census Report", currently, the majority of Chinese arts and crafts materials are on the verge of depletion, especially the wood carvings. The raw materials of Chinese art sculpture are mainly rare stones and rare woods. Currently, as for the development and utilization of rare and raw material resources, the state of disorder has not been fundamentally reversed. Some rare and raw material resources are lack of effective protection, thus becoming increasingly scarce, and even interrupted. What are the implications of the shortage of raw materials on traditional craftsmanship heritage? On the one hand, the shortage of raw materials makes some of the traditional crafts loss their original character. On the other hand, the shortage of raw materials makes some of the traditional arts and crafts on the verge of extinction. Admittedly, contradiction exists between protection of nature and human use of natural resources. We strongly support the protection of nature, and want the harmony between human and animal. Meanwhile, if the various valuable handicraft civilizations cannot be inherited, what can we do if there is no raw material one day? Shortage of raw materials can not fundamentally solve the problem. This argument is highly targeted. Since the shortage of raw materials is an indisputable fact, to resolve this situation, and to protect the maximized heritage of traditional craft, we shall believe in modern science and technology, to achieve traditional craft heritage through modern technology.

2) Traditional Crafts Materials and Modernization Restructuring. It includes the modern innovation of traditional crafts materials. Under the background of China's traditional crafts to actively carry out industrial technology, the use of modern materials and technology need not rigidly stick to the choice of natural materials. Through modern feelings, traditional craft has established the industrial creation which can reflect the spirit of contemporary people and aesthetic values. Traditional arts and crafts are the mechanized production of modern industrial society in terms of time. Traditional craft has a long history with exquisite technology, and conducts production using natural raw materials. And as for modern industrial design, it's creation body, production approach, material selection and manufacturing processes are different. The new material for science and technology research and development used by modern technology is the innovation and development on the basis of traditional crafts using modern technology to ease the problem of raw material shortage of traditional craft, enabling the combination of traditional craftsmanship and modern technology to enhance the application of electronic information technology in traditional crafts field, playing the advantages of modern technology, strengthening the application of traditional crafts natural resources and the development of modification techniques. Explore new themes and new resources to develop new arts and crafts products which are in line with market demand and adapt to the times. Highlight technical innovation and create new materials of traditional craft under the modern industrial design.

3) Traditional Craft Materials and Modernization Development. Material is one of the sources of design innovation, and innovation design will always stay on the "creative" stage without support of material innovation, which can not become a real product. A new material will also hasten the birth of a new style, and even usher in a new era of development. Meanwhile, material innovation can effectively resolve the problem of raw material shortage, but also can save costs, making it suit both the refined and popular taste. From the perspective of development value of 
traditional crafts and materials, the combinations of natural materials and technological materials, modern materials and traditional crafts, traditional crafts and modern technology, reflect the uniqueness of materials and crafts, designing out the practical and artistic artworks.

\section{B. Relationship between Traditional Craft Technology and Modern Industrial Design}

Craft technology refers to the processing method of industrial products, including raw material formulations, process route, process, process flow diagrams, process steps, process indicators, operating points and process control ranging from raw materials investment to product packaging. It does not include the product's device technology and installation techniques. Different products have different process technologies, and the same product may also have a variety of technologies. Product developers and process designers can select the most suitable product solutions and processes technology based on local resources, energy, environmental conditions, industrial policy and other specific circumstances. Traditional technology profoundly reveals the relationship between human and nature as well as the development direction of modern industrial design, applying the rule and results of Chinese traditional craft technique summarized by predecessors to today's modern industrial design [2].

Nowadays, the industrial design is evolved through continuous innovation on the basis of traditional craft technology. Its development must first follow the development of times, adapt to the needs of people's lives, continuing to draw nourishment from the real world, adding traditional expression form with the color of era, creating the artworks adapting to the needs of contemporary life. The research of relationship between traditional craft technology and modern industrial design is an important element of craft technology and theory construction. China's traditional crafts have a good international market with potential development. Under the condition of market economy, the acceleration of discovery and development of new products will render a new look for crafts industry. At the same time, the use of new technology and new material is also able to create new quality. With the rapid development of modern science and technology, the combination of technology and art, a series of industrial products has been constantly created and invented.

\section{Relationship between Traditional Craft Values and Modern Industrial Design}

To explore the design approach of modern arts and crafts, first of all the role of design shall be figured out (note: the design crafts and artwork creation referred to are two totally different concepts). From the perspective of commodity, the value of "material" is increased through the design. The added value of this part is: labor costs for organization of craftsmanship and the value of creative design wisdom; from a cultural point of view, it is the total value generated by the beautiful feeling of design works which has enhanced the cultural added value of merchandise, such as: instinctive desire beauty, cultural beauty of history and philosophy, the beauty of natural forces and so on. Then, as the best arts and crafts designers, how to achieve the value creation of this part?

Traditional technology has laid the foundation for modern process design and industrial design. In today's context of abundant material and lifestyle changes, vast majority of daily necessities are replaced by inexpensive industrial products. Advances in technology have accelerated the decline of traditional crafts. Although traditional craft has been greatly reduced in terms of practical value, it will inevitably be eliminated under the economic effects of commercial value. But it still has the irreplaceable value and significant meaning in terms of artistic value, the inheritance of national modeling characteristics and education. At the technical level, traditional process challenges the limits of human hand-eye accuracy, the practical ability of life, and the mastering of modeling beauty. On the spiritual level, it tests human's physical strength, perseverance, aesthetic sensitivity and sense of humor about life. The definition of art is to express the author's considerations based on the principles of beauty via a certain technology. Communication or even the activities or production that moves other people are all arts. Human will develop and enhance the sensitivity and moving force of artistic beauty through visual observation and tactile touch, in order to understand the existence of works and the author's inner world. The expression materials of traditional crafts cover all plane and three-dimensional graphic arts, which can be described as the integration of all arts. National spirit requirement is reflected in a nation's nationality, and the value of traditional crafts is reflected in national modeling characteristics, including national color and composition, content and form, production methods and techniques, production concepts and theoretical foundation and so on. Different countries and ethnic groups have different historical backgrounds and geographical differences, and it will naturally generate different objects shape and cultural characteristics. Traditional craft has more significance on education heritage value. Experience the object's function, observe its beauty and understand the difficulty of making it in using of objects, to recognize the value of using, loving and cherishing of object and its virtue. Seek creation inspiration from the charm of shapes, colors, patterns, lines, etc. of traditional objects, giving new life, new shape and new future to traditional crafts, in order to obtain the effect of using ancient ideas for today's reference. We will have the knowledge about historical evolution, geographic evolution, cultural evolution, and characters evolution of traditional crafts from the verification of objects... to receive the effect of tracing to the beginnings. Experience and recognize the importance of preservation technology in terms of cultural continuation and reengineering in the succession plan of object production. In other words, once a nation's traditional crafts disappear, the nation's culture will no longer exist [3].

\section{CONCLUSION}

The relationship between economic value of traditional craft and modern industrial design, with the economic development, especially the development of tourism, people 
are also beginning to develop and utilize the national traditional craft cultural resources. Business entities include state-owned, collective and private enterprises as well as small workshops, individual producers and so on. Although forms of business entities are different, the purpose is to obtain business profits. That is to say, in the production process, the development of traditional craft culture is from an economic point of view, focusing on its economic value, to obtain commercial benefits. For this purpose, in process of development, the first is selective development with the economic value as standard for selection. In modern society, the product with economic value may also be full of national characteristics, particularly the traditional craft products with rich artistic characteristics, which has certain economic value and high artistic value.

\section{REFERENCES}

[1] Zhang Xianrong, Chen Mai, Zhuang Xuan. Concept and Method of Industrial Design: Modern Design Basis [M]. Beijing: Beijing Institute of Technology Press, 2005

[2] Liu Zongyue. Translated by Xu Yiyi. Craft Culture [M]. Beijing: China Light Industry Press, 1991.

[3] Chen Yafeng. On Scientific Definition of Folk Craft [J]. Journal of Anhui Normal University (Humanities and Social Sciences), Vol. 31(2).

[4] Zhang Jianshi, Yang Zhengwen. Protection of Traditional Craft Cultural Resources of Minorities in Southwest China [J]. Journal of Southwest University for Nationalities (Humanities and Social Sciences), 2004(3).

[5] Zhang Fuye, Sun Jianjun. Traditional Craft [M]. Shenyang: Liaoning Fine Arts Publishing House, 2001. 